\title{
Physico-mechanical properties of light red meranti (Shorea spp.) and kedondong (Canarium spp.) wood heat treated in convection oven
}

\begin{abstract}
Physico-mechanical properties of light red meranti and kedondong wood heat treated in a laboratory at 160,180 and $200{ }^{\circ} \mathrm{C}$ for 5,7 and $9 \mathrm{~h}$ were investigated.Weight loss of the treated samples increased along with treatment severity. Heat treatment reduced the hygroscopicity of the wood where reduction in equilibrium moisture content and a positive moisture excluding efficiency was observed. Reduction in bending strength as function of increasing treatment temperature and time were also recorded.
\end{abstract}

Keyword: Equilibrium moisture content; Hygroscopicity; Bending strength; Moisture excluding efficiency; Thermal treatment 